\title{
Peculiaridades campesinas del Morelos rural
}

\section{Peasant peculiarities in rural Morelos}

\author{
Elsa GuzMán-Gómez* \\ Arturo León-López†
}

\begin{abstract}
In rural Morelos, the agricultural activities are still important despite the proximity and competition for resources with large cities, industrial processes and the growth of the service sector. Agricultural lands hold multiple crops both for self-supply and the market. Small farmers integrate a complex set of objectives, their proper economic resources and social and family networks. This peasant strategy denotes the viability of rural life and also provides multiple services to society.
\end{abstract}

Keywords: peasant security, rural multi-activity, market, peasant strategy.

\section{Resumen}

En el campo morelense la actividad rural es aún importante a pesar de la cercanía y la competencia de recursos con grandes urbes, procesos industriales y crecimiento del sector terciario. Las tierras agrícolas sostienen múltiples cultivos destinados al autoabasto y al mercado. Los pequeños productores, desde la organización de su grupo familiar, recursos económicos propios y redes familiares y sociales, integran un complejo de objetivos, decisiones y actividades con las que se estructuran estrategias de reproducción campesina que marcan la viabilidad de la forma de vida rural, además de brindar múltiples servicios a la sociedad general.

Palabras clave: seguridad campesina, multiactividad rural, mercado agrícola, estrategias campesinas.

* Universidad Autónoma del Estado de Morelos, México. Correo-e: elsaguzmang@yahoo. com.mx

† Universidad Autónoma Metropolitana, unidad Xochimilco, México. Correo-e: jaleon@correo. xoc.uam.mx 


\section{Introducción}

Las transformaciones en el mundo en las últimas décadas suceden a gran velocidad y son complejas y profundas. Dentro de ellas es posible distinguir algunas tendencias generales como el desplazamiento de los ámbitos culturales tradicionales, la tecnología como bastión de cambio, la preponderancia de los procesos urbanos frente a los rurales, y, de manera particular, la disminución del peso de los espacios y elementos rurales.

Esto lleva a reconocer la existencia de nuevos arreglos y cotidianidades en las formas de vida rurales, nuevas interacciones entre lo rural y urbano, así como diferentes inserciones en la sociedad por parte de la población del campo.

Hace un siglo, México era un país fundamentalmente rural, hoy en día la preponderancia poblacional y las dinámicas económicas muestran la preeminencia de las urbes, de los sectores económicos secundarios y terciarios. De igual modo, es notoria la persistencia de una población rural minoritaria frente al total nacional, ubicada en una situación reconocida de marginación social y económica pero que no ha desaparecido y continúa teniendo presencia y funciones indispensables para la dinámica general nacional.

La población rural, que aumenta aún en números naturales, tiene bajo su resguardo grandes superficies de territorio; por ejemplo, sólo en cuanto a las tierras de propiedad social, se cuentan 4.8 millones de ejidatarios y comuneros campesinos con 105 millones de hectáreas, en donde se encuentran las zonas forestales, agrícolas, ganaderas y cuerpos de agua que cumplen funciones de generación de alimentos y productos para el mercado nacional e internacional, madera, múltiples productos de recolección, de captación de agua, generación de oxígeno, regulación del clima, etcétera; todos estos son productos y funciones imprescindibles para la vida urbana, el desarrollo industrial, la dinámica de los mercados y la acumulación de capital.

En las zonas rurales se guardan múltiples elementos culturales que resguardan la cultura tradicional cambiante y que conforman un amplio y complejo mosaico de visiones del mundo, conocimientos, ritos, prácticas, redes sociales, etcétera, que son base y parte de la riqueza cultural de nuestro país.

El reconocimiento de las transformaciones y tendencias actuales, que incluyen tanto los nuevos procesos como las permanencias en el conjunto de la población y regiones del país, lleva, desde nuestra perspectiva, a la necesidad de reconocer tanto lo irreversible de los cambios como la complejidad de ellos. Estos fenómenos no se dan de manera llana y unilineal sino que tienen como base historias y objetivos distintos que entre- 
lazan procesos de resistencia desde las culturas campesinas que derivan en distintos balances urbanos-rurales (frente a la visión de la mera disolución de los elementos rurales por los urbanos) y nuevas concepciones de lo rural (frente a las visiones tradicionales de caracterización de lo rural a partir de una vida aislada, atrasada, meramente agrícola). Ello llevaría a un cambio de consideración de lo campesino, es decir, hablar de los campesinos de hoy.

Los campesinos de México conforman un sector subordinado de las visiones actuales de la modernización, de los grandes intereses del modelo de desarrollo del país y de las tendencias globales de cambio. Pero la persistencia de dichos grupos y la aportación de elementos indispensables para el desarrollo nacional dejan ver que estas grandes tendencias y nuevos procesos se encuentran entreverados de resistencias y presencias campesinas.

Con esta perspectiva, el presente trabajo es producto parcial de una investigación amplia que tiene como objetivo la comprensión de las estrategias de vida de los campesinos del estado de Morelos realizado para entender las maneras particulares en que estos grupos subsisten en una sociedad cambiante, hacen frente y se insertan al mercado con múltiples procesos ajenos y contrarios a lo campesino; asimismo, se reconoce que esta presencia campesina tiene elementos que dificultan su propia condición de reproducción tal como las contradicciones con el crecimiento urbano, la venta de tierras agrícolas, las perspectivas de salida de los jóvenes, el envejecimiento ejidal, etcétera, que forman parte de la realidad rural actual.

Este trabajo contiene, en una primera parte, el análisis de la presencia y recursos campesinos en el estado: dibuja al Morelos rural y para ello se retoma información estadística oficial y se dirige hacia el reconocimiento del trabajo y valor generado por este grupo social. Esta situación se enmarca en las condiciones complejas y diversas frente a las tendencias importantes de crecimiento urbano y presión sobre los recursos y actividades rurales. En la siguiente parte del trabajo se plasman los ejes principales de las estrategias campesinas reconocidas en el transcurso de dicha investigación, se retoman algunos trabajos anteriores en el marco de la misma, y se articulan alrededor del avance de las indagaciones.

A través de recorridos en las parcelas, pláticas y entrevistas en los pueblos del norte y del poniente de Morelos hechas en las distintas plazas de mercado a productores, mujeres, jóvenes y comerciantes, se han ido recopilando las condiciones, problemáticas, historias de los procesos productivos y las relaciones que en el campo de Morelos se llevan a cabo. De esta manera, se prioriza la perspectiva de los propios actores como eje del mismo análisis. A partir de lo anterior se han sistematizado las estra- 
tegias a través de dos ejes principales: el primero que se reconoce tiene como objetivo la seguridad, y el segundo el de vinculación al mercado. Ambos se complementan como parte de un proceso complejo presente dentro de grandes cambios y tendencias de la sociedad. Dichas estrategias se alternan con actividades no agrícolas, e incluso no rurales, así como con la negociación con múltiples y crecientes procesos contrarios a la reproducción campesina.

Es así que interesa reconocer y profundizar en las maneras particulares, con todas las complejidades y contradicciones en que los campesinos morelenses logran seguir presentes dentro de una historia y condiciones actuales generales adversas a su propia cultura y subsistencia.

\section{Morelos rural}

Dentro del escenario nacional de transformaciones aceleradas en el que domina la modernización, urbanización y transición poblacional de las últimas décadas, el estado de Morelos en su conjunto se ve afectado e influenciado fuertemente por las tendencias nacionales y mundiales, dada su cercanía y gran interacción con el centro del país. Así, es notorio el crecimiento poblacional como una de las características más importantes de los cambios estatales, con una expansión y concentración de las manchas urbanas.

\subsection{Transición poblacional y urbanización difusa}

El estado de Morelos colinda con la capital nacional; ocupa un territorio pequeño de 4,960 $\mathrm{km}^{2}$ con alta densidad de población $\left(323 \mathrm{hab} / \mathrm{km}^{2}\right.$ ) como producto del incremento poblacional local de las últimas décadas y por procesos de inmigración de estados como Guerrero y el Distrito Federal (en la década de los ochenta). Este cambio ha sido contundente desde la segunda mitad del siglo xx, y se puede ver que de 1970 a 2010 la población estatal pasó de 616,119 personas a 1,777,227 (INEGI, 2011), lo que significa un aumento de 2.8 veces. En estos cuarenta ańos la población del estado ha tenido una transición al pasar de ser eminentemente rural a predominantemente urbana. Para 1970 la población rural ${ }^{1}$ era de 30.1\% del total estatal, mientras que en el año 2010 se registró 16\% (INEGi, 2011).

Esta transición poblacional hacia lo urbano ha influido en la disminución de la representatividad de la Población Económicamente Activa

\footnotetext{
${ }^{1}$ En este apartado se habla de población rural que habita en localidades con menos de 2,500 habitantes.
} 
(PEA) agropecuaria, con respecto a la PEA total. En 1970 la PEA agropecuaria representaba $47 \%$ de la total, cuando para el 2003 cayó a 13\%, en tanto se registraron aumentos en la PEA del sector secundario y terciario, llegando a $25.8 \%$ y $57.0 \%$, respectivamente.

La población se concentró en las zonas urbanas dando lugar a la expansión de las principales ciudades del estado: Cuernavaca, Jiutepec, Temixco, Emiliano Zapata, Xochitepec, Ocotepec, Yautepec, Oaxtepec, Cocoyoc, Cuautla y Ayala. Así, la población de los seis municipios urbanos representa más de $60 \%$ de la población estatal.

Dichas tendencias implican un aumento acelerado en la demanda de viviendas y servicios, así como cambios en la actividad laboral de las personas con nuevos balances o desbalances en el uso y distribución de los recursos.

Así, en Morelos se ha manifestado un crecimiento caótico de las periferias conurbadas con alta densidad de población, caracterizado por la falta de planeación en la provisión y administración de servicios cuyos casos representativos están dados por los complejos habitacionales que desde los años setenta han desarrollado dos empresas principalmente, la Corporación GEO (a partir de 1973) y el consorcio ARA (desde 1977), cuya incidencia se ha acentuado al filo del siglo Xxi. Asimismo, la vivienda de tipo residencial en fraccionamientos de lujo ha tenido auge en los últimos años lo cual ha intensificado la venta de la tierra, legal e irregular, así como la competencia por el uso del suelo, la fragmentación de territorios productivos y forestales con consecuentes disputas por la disponibilidad de agua y la contaminación de la misma.

A esto se suma la particularidad morelense del atractivo turístico dado por la cercanía al Distrito Federal, por el clima cálido y por la belleza de sus paisajes. Esto ha derivado en la especulación de la tierra por empresas inmobiliarias, fortalecida por la puerta abierta a la venta de la tierra ejidal y comunal a partir de las modificaciones al artículo 27 constitucional en el marco del impulso a nuevas actividades productivas y turísticas, distintas a la agricultura. El fomento turístico en el estado ha significado el crecimiento del sector económico de servicios, tanto en las zonas urbanas como rurales. Esto provoca procesos importantes de deforestación de bosques y selvas, erosión de tierras fértiles, calculada en $0.3 \%$ anual (Contreras et al., 2006), sobreexplotación y contaminación de los acuíferos subterráneos y superficiales por desechos industriales, y desbordamiento de desechos de basura. Además de la incapacidad de manejarlos adecuadamente, se utilizan tiraderos a cielo abierto sin control de residuos tóxicos ni protección contra accidentes en diversas zonas rurales (Contreras et al., 2006). 
La expansión urbana se relaciona fuertemente con las transformaciones en la agricultura y la adopción de la modernización tecnológica. Por un lado, el crecimiento de la población urbana forma parte de una tendencia nacional que da lugar a la ampliación del mercado de alimentos, lo que permite a los productores morelenses incorporarse al cultivo de productos de alta demanda nacional y redituabilidad potencial, como es el caso de hortalizas, que se adaptan bien a las tierras y prácticas campesinas morelenses. Por otro lado, la urbanización abre los caminos a carreteras hacia todos los rincones del estado de Morelos y acerca la entrada de la tecnología agrícola, pero también integra nuevas pautas de consumo. Esto significa que, como parte del escenario rural, se vislumbran servicios, estructuras y múltiples elementos propios de las ciudades, lo que se considera como una urbanización difusa (Hervieu y Viard, 2001) ${ }^{2}$ en los distintos ámbitos de la vida rural (social, económica, productiva, etcétera).

La cercanía entre las zonas rurales y las urbanas es muy clara en el estado de Morelos; existe una red de carreteras y caminos que llegan a las 833 localidades del estado y comunica a las 753 localidades de menos de 2,500 habitantes, interconectándolas con las localidades medias distribuidas a lo largo de todo el territorio estatal, así como con las 23 de más de 10,000 habitantes (INEGI, 2003). Al mismo tiempo, en la distribución de localidades y carreteras, se encuentran delimitadas las zonas de expansión urbana, concentradas en tres puntos en el norte y sur-poniente del estado, desde donde se articula la distribución de servicios y los flujos de migración y movilidad laboral de la población. Esta red de comunicación, además de dar lugar a los traslados de la población local y mercancías, también inserta flujos con otros estados y es parte importante de las influencias y transformaciones del exterior hacia las comunidades rurales.

\subsection{Producción agropecuaria: ajuste estructural y trabajo campesino}

Como parte de las transformaciones de las últimas décadas, el final del siglo xx y los ańos subsecuentes han sido especialmente difíciles para los campesinos de todo el país, entre ellos los morelenses. Los campesinos han sido llevados a márgenes de la explotación dentro del proceso de ajuste estructural que implica la definición neoliberal en la política nacional. Se ha girado la política agrícola hacia la desregulación del mercado y la apertura de la frontera nacional al mercado mundial mediante la

\footnotetext{
${ }^{2}$ Hervieu y Viard (2001) conciben la urbanización difusa ante la articulación de elementos considerados urbanos como la escolarización, los medios masivos de comunicación y el potencial de movilidad en los pueblos rurales (es decir, fuera de la ciudad) que se vinculan con una vida de acuerdo a ciertos ritmos de la naturaleza, el arraigo de la tierra y otros elementos tradicionales.
} 
implementación del Tratado de Libre Comercio con Norteamérica y otros convenios en los que se priorizan las importaciones de productos alimentarios básicos y se limitan las exportaciones (Rubio, 2006).

En el marco en el que la disminución del peso económico del sector agrícola (INEGI, 2011) es causa y consecuencia (Presidencia de la República, 2008) ${ }^{3}$, las inversiones públicas para el campo se han restringido mediante la desestructuración del sistema de instituciones oficiales y paraestatales que conformaban la red de servicios agrícolas, ${ }^{4}$ los cuales, a partir de los noventa, son limitados a las políticas agrícolas con planteamientos asistencialistas o políticas focalizadas, que sostienen subsidios diferenciados, sin beneficios a pequeños y medianos productores (Fox y Haight, 2010), y que por el contrario, impulsan a las empresas transnacionales regionales para la producción externa.

Entonces, el conjunto de transformaciones que se vislumbran en el estado de Morelos, dentro de la lógica o modelo neoliberal, lleva a que los recursos naturales y productivos sean dinamizados en el marco del mercado libre, lo que profundiza los enfrentamientos de intereses de diversos agentes y comunidades campesinas, generando profundos conflictos. Esta disputa de espacios y recursos confronta a agentes tales como comerciantes, agencias inmobiliarias, proveedores de insumos agrícolas, y todo tipo de intermediarios de productos agrícolas.

No obstante que los procesos urbanos trastocan las actividades agrícolas de los productores de Morelos, aún es posible distinguir que en el marco productivo estatal las pequeñas unidades campesinas mantienen una actividad que sostiene gran parte del territorio en producción. Lejos de ver el campo abandonado, existe intensa actividad en las distintas regiones en las épocas de siembra, cultivo y cosecha, especialmente en el ciclo de temporal (Sánchez y Saldaña, 2010) con precipitación abundante para el cultivo en el ciclo de primavera-verano.

En el estado de Morelos, año con año, los pequeños productores, siembran múltiples cultivos: de temporal, riego, en ciclo de primavera y de invierno, así como de autoconsumo y con fines comerciales. Se ocupan grandes superficies con pequeñas parcelas, formando un mosaico en el paisaje diverso y cambiante.

La mayor parte de la superficie del territorio estatal (396,526 hectáreas equivalente a $80 \%$ ) se encuentra bajo régimen de tenencia de propiedad social, considerados los 201 ejidos y 33 comunidades agrarias del estado,

${ }^{3}$ El porcentaje del Producto Interno Bruto (PIB) del sector económico primario (agropecuario, forestal y pesquero) ha disminuido dentro del total del peso de la economía nacional, de tal manera que en los años que van del siglo xxi, a nivel nacional, sólo $5.5 \%$ del pIB corresponde a este sector, y a nivel estatal alrededor del 10 por ciento.

${ }^{4}$ Sistemas de crédito y seguro agrícola, Conasupo, Inmecafe, Conafrut, Pronase, Fertimex, etcétera. 
agregándose a ellas tierras de minifundio de propiedad privada que se intercalan en un mosaico complejo y cambiante de usos de la tierra morelense. Se considera que sólo $8 \%$ de las unidades productivas son de carácter empresarial (INEGI, 1994), el resto es considerado de tipo campesino, no comercial. Esto último no significa, como veremos más adelante, que los campesinos no lleven sus productos al mercado, pues ésta no es la única finalidad de la unidad de producción.

Estos cultivos se encuentran en manos de 64,157 ejidatarios y comuneros, y 14,047 posesionarios, y se extienden a lo largo de 205,592 hectáreas parceladas. El uso predominante que las tierras sociales tienen es el agrícola pues 222 ejidos y comunidades de las 234 existentes en el estado la tienen como actividad presente; 199 ejidos se dedican a las actividades ganaderas y 33 a la recolección de recursos naturales (INEGI, 2008).

Los datos presentan, por un lado, que las parcelas disponibles corresponden a la denominación de minifundio, en tanto el promedio de la extensión de la parcela de propiedad social que cada sujeto de derecho (ejidatario, comunero y posesionario) tiene es de 2.6 hectáreas, siendo una de las cifras más pequeñas a nivel nacional. Además, la mayoría de las tierras son de temporal (75\% aproximadamente, en concreto 147 ejidos, y más de 90,000 hectáreas). Por otro lado, en 131 ejidos y comunidades se llevan a cabo también actividades como extracción de materiales para construcción (36) y otros minerales (2), pesqueras (25), artesanales (15), industriales (8), turísticas (27) y acuícolas (39) (INEGI, 2008).

El escenario productivo muestra múltiples unidades, en su mayoría familiares, de las que forman parte los jóvenes. Si bien se reconoce que en 66 ejidos y comunidades la mayoría de los jóvenes no permanecen en sus comunidades y salen preferentemente a Estados Unidos como medida de búsqueda de empleo y recursos, aún se tienen 168 comunidades en que la mayoría de los jóvenes permanecen en sus localidades y se integran a las actividades locales, preponderantemente agropecuarias (INEGI, 2008).

Estas unidades productivas, de pequeña y mediana producción, de acuerdo a las distintas regiones del estado, las aptitudes de la tierra y posibilidades de riego sostienen un mosaico amplio de cultivos. En el 2006 se sembraron 117,284.42 hectáreas, de las cuales 92,550.10 se cultivaron en el ciclo de temporal de lluvias, y 34,734.32 bajo condiciones de riego (sIAP-Sagarpa, 2010).

El principal cultivo es el sorgo que ocupa la mayor superficie ante el impulso oficial y un mercado en crecimiento. Esta expansión ha sustituido tierras anteriormente maiceras, producto que aún se siembra en todos los municipios del estado, especialmente en el ciclo de temporal. La tierra ocupada por el maíz ha disminuido significativamente pues la mayor parte de los productores destina lo poco que siembra al consumo propio 
y a la venta de mazorca fresca y de maíz criollo pozolero, que tiene un mercado amplio.

Las tierras de temporal también se cubren de múltiples variedades de frijol, jitomate, tomate verde, pepino, avena forrajera, cacahuate, nopal, durazno y aguacate, como cultivos principales, además de al menos 40 más en pequeñas proporciones. En condiciones de riego se destaca la siembra de elote, maíz para grano, arroz, frijol ejotero, cańa de azúcar y múltiples hortalizas (especialmente cebolla, pepino y calabacita) y flores que, a pequeña escala, se cultivan y venden en plazas locales e incluso llegan al mercado nacional (sIAP-Sagarpa, 2010).

Como contraparte de la actividad agropecuaria local se observan cada vez más los procesos de migración. Si bien en el estado estos no se consideran procesos generalizados, se manifiestan de manera heterogénea en los diferentes municipios de acuerdo con la capacidad de generar empleos y con la historia de migración y redes sociales construidas. La población migrante de Morelos se calcula en 44,426 para el año 2000, de los cuales 31,525 son hombres y 12,901 son mujeres, con una edad promedio de 26.81 años los hombres y 24.16 , las mujeres; $6.44 \%$ de las familias del estado reciben remesas que se invierten, principalmente, en la agricultura. En los municipios del norte la migración es menos recurrente, en contraste con Axochiapan en el sur y Coatlán del Río, en el poniente del estado, donde los flujos migratorios son más intensos. Seis municipios cuentan con alta migración, 12 de ellos con actividad migratoria media y 15 con baja migración (Conapo, 2000). ${ }^{5}$

Entonces, desde los procesos productivos agrícolas y otras actividades que se ejecutan, la mayor parte de las familias mantiene su residencia fija en las localidades rurales y, desde ellas, se relacionan con múltiples agentes y procesos externos, al igual que reciben se vinculan con una población móvil que labora y habita por tiempos distintos fuera de los pueblos o en ellos, pero realizando actividades del sector secundario y terciario, lo que complejiza los procesos rurales. De esta manera, las comunidades campesinas usan y sostienen sus recursos de diversas formas: dentro de múltiples procesos, con objetivos y en sentidos diferentes, así como con contrapuestos tales como el crecimiento urbano, deterioro del suelo, incremento de vías y medios de comunicación, especulación del mercado, aunadas a viejas y nuevas formas de acumulación de capital.

\footnotetext{
${ }^{5}$ Estimaciones de Conapo con base en el XII Censo de Población y vivienda 2000.
} 


\section{Estrategias campesinas de vida}

Para entender la presencia de los grupos campesinos en la sociedad actual, frente al conjunto de procesos opuestos a la vida y lógicas rurales en las condiciones de subordinación y dificultad de negociación existentes, es necesario analizar la forma en la que dichos grupos llevan a cabo sus actividades para sobrevivir y sus lógicas como estrategias de vida.

Esta definición de actividades contempla un conjunto de decisiones culturales que se toman frente a las condiciones, restricciones, necesidades y potencialidades que los grupos y unidades familiares campesinas vislumbran como formas de avanzar hacia donde se puede y se quiere continuar.

A partir de dichas estrategias los campesinos buscan adaptarse dinámicamente, lo mejor posible, a los cambios globales, a la tecnología, al mercado y a los elementos culturales externos, es decir, representan las maneras en que la reproducción campesina (su forma de vida, relaciones familiares y parentales, arraigos a la tierra, a las fiestas, a los pueblos, etcétera) se adecua a las condiciones globales de la sociedad y a las necesidades y posibilidades de las comunidades y unidades familiares. Se generan pluralidades ante las maneras de relacionarse, dice Bartra (2010), bajo múltiples patrones tecnológicos, productivos, societarios y simbólicos, y modalidades de insertarse al sistema mayor (como asalariados, a través del autoconsumo y la agricultura comercial y asociativa).

Las estrategias de vida se integran por un complejo de actividades, objetivos, recursos y organización, necesarios para la reproducción social de las familias y los grupos campesinos. En las condiciones actuales, en Morelos, se conjugan una serie de actividades agrícolas como eje de la vida rural, pero muchas veces no suficiente para satisfacer las necesidades de la familia.

Así, en Morelos existen diversas maneras de organizar las estrategias, en esta investigación se ha distinguido la combinación y complementariedad de dos componentes fundamentales: un componente de seguridad y otro de vinculación al mercado, los que a su vez conjuntan diferentes actividades.

El componente de seguridad está integrado por el conjunto de actividades y objetivos que desde los espacios domésticos y productivos, no comerciales, producen recursos básicos para la reproducción campesina sin el carácter de la incertidumbre, bajo lógicas campesinas. El elemento principal de este componente es el trabajo invertido para la obtención de bienes de consumo o bienes no materiales, los cuales garantizan la seguridad de la familia, en tanto dan lugar a la reproducción biológica, material, generacional, de la fuerza de trabajo, de la transmisión cultural y del 
sustento alimenticio, así como protección y cobijo. Bajo estos ámbitos se generan productos para el autosustento y autoconsumo, que no pasan por los circuitos del mercado o circulan en vías de intercambios de corto alcance (interfamiliares y comunitarios).

Dentro del marco socioeconómico campesino, la vinculación al mercado representa la posibilidad de obtener ingresos monetarios a costa de una inserción desventajosa en el marco de la sociedad global. Esta es la manera en que el campesinado de hoy, como grupo social, se ha acomodado en la sociedad y en el orden económico (Bartra, 2010), y lo reproduce. El mercado es un espacio de subordinación y transferencia de excedentes del trabajo campesino hacia otros agentes de la sociedad; es el lugar en el que en última instancia se refieren los procesos de acumulación y reproducción de capital, frente a los cuales los campesinos no cuentan con elementos para una negociación favorable o equitativa. Dada esta situación, la búsqueda de ingreso económico representa la participación en mecanismos de riesgo e incertidumbre, pues no sólo es un hecho la subordinación, sino que, muchas veces, significa la pérdida de la inversión y de ganancias. No obstante, los campesinos se ven en la necesidad de recurrir a este espacio para obtener ingresos necesarios para subsistir $y$, desde el conjunto de su estrategia, tratan de hacerlo de manera menos desventajosa, garantizando su propia reproducción.

\subsection{Componente de seguridad. De lo doméstico al autoconsumo}

La seguridad como valor, objetivo y conjunto de prácticas dentro de la forma de vida campesina se funda en el origen y persistencia de estos grupos a lo largo de la historia en la sociedad mexicana; es una condición indispensable y básica para garantizar una forma de vida bajo condiciones de incertidumbre, de vulnerabiliadad y permanentes riesgos, por lo que forma parte del proceso de construcción de la cultura campesina.

\subsubsection{Lo doméstico}

En los diferentes acercamientos y estudios campesinos en Morelos se corrobora que la familia es la unidad de los grupos de este sector (LeónLópez y Guzmán-Gómez, 2004, 2005 y Guzmán-Gómez y León-López, 2008 a y b). Esta unidad familiar es un grupo básicamente de tipo nuclear (aunque puedan existir integrantes sin vínculos familiares directos, ni ser padres o hijos), cuya organización incluye la integración de los roles de los diferentes miembros de la unidad. La lógica general de la organización familiar es distribuir la participación y las actividades entre dos funciones: domésticas y productivas, las cuales tienen sesgos definidos de género y 
edad. Las características que dicha organización toma se dan de acuerdo a la etapa del ciclo de vida familiar, a lo que corresponden las necesidades y capacidades de hijos, padres y demás integrantes.

Las familias en etapas de formación o crecimiento de acuerdo con el ciclo familiar tienden a trabajar y subordinarse a las unidades paternas, especialmente si padres o suegros cuentan con tierras; las unidades familiares maduras con hijos independientes cuentan con menos fuerza de trabajo familiar y contratan jornaleros para las actividades productivas. En las etapas intermedias, los hijos participan en las actividades de la unidad familiar colaborando y, a su vez, aprendiendo; posteriormente se independizan formando nuevas unidades bajo procesos de colaboración mutua.

Se vislumbra una gran movilidad de los jóvenes, quienes optan por distintos caminos, de acuerdo con las condiciones cambiantes de las comunidades y regiones (disponibilidad de tierra, posibilidades de inserción laboral extra agrícola, dinámica agrícola regional, etcétera). Unos se integran a las actividades agropecuarias y domésticas, pero no todos permanecen en la casa familiar, algunos prefieren abandonar el campo y buscar opciones fuera.

Al frente de la unidad familiar se encuentra una mujer, aunque no todas permanezcan en el hogar, pues algunas madres o hijas trabajan fuera o estudian. Existe un sesgo de autoridad masculina, típica en las estructuras familiares patriarcales, de manera que la mujer, sin demeritar el intenso trabajo y responsabilidad, en lo general, tiene menor capacidad de decisión como precepto y en el ejercicio real de las determinaciones. Este aspecto sobresale en los momentos en que el hombre migra por tiempo prolongado, sin que se desvanezca la idea de la jefatura masculina con derecho y responsabilidad de tomar decisiones sobre el uso de los recursos, las actividades de los integrantes y los nuevos destinos de los hijos. De cualquier modo, la presencia del trabajo y responsabilidad femenina continúa como base de la permanencia de la casa, la unidad doméstica y la organización familiar.

Las actividades que se encuentran en el ámbito doméstico, corresponden estrictamente a las funciones de la casa, y se refieren a las que dan lugar a la alimentación, cobijo, descanso y educación. Tienen que ver con tareas domésticas de aseo de la casa, ropa, prepararación de los alimentos diarios, los acondicionamientos necesarios de insumos (cultivados o recolectados), el traslado de los hijos a la escuela y el transmitir los conocimientos básicos de la organización del entorno doméstico. La permanencia de este espacio no deja de integrar múltiples modificaciones, pues a éste se agrega, constantemente, la presencia de aparatos y servicios, así como nuevas costumbres, ideas, ritmos de vida y formas de trasmisión de 
la cultura. De igual manera, esta persistencia permite organizar y adaptar múltiples interacciones con los ámbitos productivos y de movilidad.

\subsubsection{Los traspatios}

Los traspatios, como en la mayor parte de los espacios rurales en México, se encuentran presentes en las casas campesinas de Morelos; estos contienen un carácter multifacético que permiten la vinculación de la vida doméstica con la productiva, con diversas funciones y fisonomías adecuadas a los agrohábitats y a las dinámicas agrícolas y de mercado. Correspondientes a los minifundios, los traspatios también son reducidos, pues difícilmente superan los $1000 \mathrm{~m}^{2}$, y se encuentran en un proceso de subdivisión permanente para la construcción de casas de los hijos. Sin embargo, en los sub-espacios se mantienen distintas funciones.

En los traspatios campesinos se encuentran los servicios adecuados a las funciones domésticas, tal es el caso del pozo de agua, la leña para el fogón y el comal al lado de la estufa de gas, así como el espacio de esparcimiento y recepción de visitas, necesario en las dinámicas de las comunidades, con enramadas, especialmente en las zonas más cálidas.

Los espacios vinculados a la producción permiten guardar las herramientas de trabajo e implementos como varas de espalderas de cultivos hortícolas, mientras que en la temporada de secas, cuando no se siembra, ahí se depositan bombas, agroquímicos, tractores, camionetas, cajas e implementos para el manejo de los cultivos comerciales, etcétera. Estos espacios se relacionan también con el acondicionamiento de cosechas, es decir, desgranado de maíz y desenvainado de frijol; cría y resguardo de animales como gallinas, puercos, caballos, becerros en engorda; así como producción permanente de plantas como mangos, aguacates, tamarindos, duraznos, cítricos, matas de jitomate, chile, calabaza, frijol, hierbas aromáticas y medicinales, y por supuesto, de ornato, que en ningún traspatio faltan.

En un recuento, en los traspatios del poniente de Morelos de una zona semicálida de trópico seco se encontraron al menos 12 especies de árboles y animales de especies menores (Guzmán-Gómez, 2004), mientras que en la zona de la selva del sur del estado (en los traspatios de Quilamula), en un ambiente más húmedo, se reconocieron 115 especies en total (Morales, 2007). Por otra parte, se reconoce que en el oriente, a orillas del río Amatzinac, los huertos familiares han cumplido la función de garantizar el poblamiento y crecimiento de pueblos a lo largo de la historia, al proveer elementos para la reproducción y garantizar el trabajo durante todo el año (León-López y Guzmán-Gómez, 2004). 
Los productos que se obtienen y se destinan al consumo familiar son garantía cercana del suministro de nutrientes diversos sin inversión directa de dinero. Los productos se intercambian entre las casas, familiares y amigos; compensan la invasión de dulces y alimentos chatarra tan difundidos actualmente. Cuando la producción excede el consumo se vende en las plazas locales; estos productos son ciruelas, guajes, tamarindo, maíz, hojas de totomoxtle, aguacates, granadas, nopales picados, limones, etcétera. La venta de algunos productos del traspatio cumple funciones de ahorro familiar y fortalece la seguridad económica. Asimismo, se crían algunos puercos, gallinas, cabezas de ganado mayor que implican cuidados a lo largo de cierto periodo y generan gastos menores, pero de alguna manera posibilitan pagos económicos altos de manera puntual (fiestas, emergencia médica, accidente, salidas migratorias, etcétera).

Los alrededores del traspatio y los caminos hacia las milpas son los espacios de recolección, aunque las áreas de uso común se encuentran con problemas de deterioro ambiental; aún se practica la recolección de leña, hongos, hierbas, caza de animales, frutos silvestres, etcétera (León-López y Guzmán-Gómez, 1999). Esta actividad, en general, cubre usos para la familia, pero en ocasiones los productos se venden, tal es el caso de la extracción de resinas, algunas semillas, materiales utilizados para artesanías y animales.

\subsubsection{El maiz}

El traspatio y sus alrededores se intercomunican con la parcela para lograr una producción mayor de autoconsumo de productos como maíz, frijol y calabaza, principalmente.

En Morelos, el maíz se siembra en todos los municipios, prácticamente en todos los pueblos rurales, y es cercano a todas las unidades familiares. Todas las tierras en Morelos han cultivado maíz alguna vez, así como todos los campesinos lo han sembrado en cosechas propias o ajenas. Anteriormente, la mayor parte de las cosechas se destinaba al mercado y una parte al consumo familiar, actualmente la mayor producción es para autoabasto, es decir, las cantidades y destinos se van restringiendo, y en la mayoría de los casos, el consumo familiar es la única justificación de la producción agrícola, independientemente de que en alguna época del año se compre maíz para complementar las necesidades. El cultivo del maíz y el conjunto de prácticas que se realizan en torno a su producción organizan el conjunto de actividades agrícolas y configuran la base de la seguridad campesina; al ser alimentos que se siembran con recursos propios, se definen a partir de la autonomía como esencia campesina, sostenida por decisiones, conocimientos, experiencias y recursos propios. 
Con el maíz se surte el alimento básico, la calidad reconocida por los campesinos en términos del sabor preferido de las tortillas, el valor de la preparación en casa, de la confianza por lo auténtico, además de todos los otros productos derivados del maíz -elotes, atole, pozole, gorditas, tamales, hojas, forrajes, combustible-. También se articula la inserción de este producto al mercado, bien sea el convencional, como base de un precio estandarizado que no paga la inversión realizada, hasta un mercado de calidad que paga precios altos por productos específicos como tortillas hechas a mano. El maíz pozolero, característico del norte del estado, se lleva a un mercado amplio nacional y quizá hasta internacional, así como las hojas de mazorca de éste, preferidas para envolver tamales. El maíz azul, pinto y negro, que se cultiva en distintos pueblos, plazas y ciudades del estado, es adecuado para algunos antojitos.

En las plazas locales y municipales se da la comercialización de maíz en sus diferentes tipos (azul, pepitilla, pozolero o ancho, criollo-híbrido, híbrido) y de frijoles de diversas variedades (cacahuate, peruano, vaquita, bola, de caña, negro, flor de mayo, cuaresmero, entre otros), así como de calabazas, guajes, habas y cacahuates. Todos estos productos se venden y compran para el consumo en todas las casas. Esto permite ver que la seguridad campesina se articula en las parcelas y comunidades. Por supuesto que también se relaciona con las influencias externas, urbanas y no campesinas, al requerir cada vez más el consumo de productos industrializados, lo que muestra la intersección de mosaicos donde lo campesino subsiste y resalta la persistencia de los objetivos de seguridad.

El ámbito de seguridad sustenta subsistencia material pero también reproducción de la cultura; al permitir la transmisión de conocimientos, así como su recreación, garantiza el primer paso de la socialización de sus integrantes hacia las interacciones productivas, laborales y sociales. De esta manera, podemos decir que la base familiar representa la cotidianidad que articula la permanencia con la movilidad, pues los espacios domésticos, de autoconsumo, producción a pequeña escala y ahorro campesino generan estabilidad e incluso sientan la base de actividades de generación de ingresos económicos -agrícolas o no agrícolas- que movilizan y retienen la fuerza de trabajo, generan empleos diversos y sostienen procesos amplios de desarrollos locales y regionales.

\subsection{Componente de vinculación al mercado: de la diversidad agrícola al empleo externo}

Para los campesinos, la contraparte de la seguridad es la participación en el mercado con los productos de su trabajo o con su propia fuerza de trabajo. La oferta de estas mercancías campesinas significa un intercambio 
desigual y desequilibrado, con prejuicios claros para los campesinos, ya que, en general, no cuentan con las mejores condiciones de negociación dentro de los mecanismos de fijación de calidad, precio y contratos de trabajo. Esta desventaja es contrarrestada con el conjunto de actividades de la estrategia.

\subsubsection{Diversidad agricola}

En Morelos, además del maíz para autoconsumo, existe una gran gama de productos agrícolas que se destinan al mercado con el objetivo de venderse y obtener ingresos económicos: cada productor los distribuye en sus tierras. La agricultura es sostenida por la vocación y experiencia agrícola de los campesinos y la capacidad de adecuarse y agregar conocimientos a ésta, es decir, esta inserción al mercado se sustenta en las bases de la cultura campesina, así como en la autonomía sobre su experiencia.

Paradójicamente a lo anterior, la comercialización se realiza, en general, de manera subordinada para los pequeños productores, ya que se da a través de una red de intermediarios, quienes establecen los vínculos para llevar los productos de los campesinos de la región desde las parcelas o lugares locales de acopio hacia el mercado, esto conlleva aún más desventajas pues, si en realidad los campesinos no pueden negociar los precios de sus cosechas, al encontrarse determinados por mecanismos generales en la central de abastos de la ciudad de México, tampoco pueden participar en las condiciones particulares de la venta, situación que los vuelve más dependientes a los intermediarios.

Las formas de comercialización y los agentes involucrados se han diversificado, así como la severidad de dicha subordinación en algunos casos, y esto depende de los recursos económicos, materiales y relacionales con que cada productor cuente, pues les permitirá acomodar sus cosechas con menos desventajas. La comercialización puede darse a pie de parcela, a granel, con productos seleccionados y empacados, a intermediarios y fleteros o directamente a la central de abastos de Cuautla o de la ciudad de México. Algunos, con mayores ventajas en la comercialización, elegirán de acuerdo a los precios vigentes al vendedor más conveniente de una serie de relaciones previamente establecidas (bodegueros, comerciantes externos, fleteros, etcétera).

Existe una gran variedad de cultivos, algunos ya cuentan con puntos de venta específicos y establecidos, por ejemplo, una gran parte de la caña de azúcar se tiene precontratada con el ingenio, igualmente el arroz con el molino, en convenios cercanos a la agricultura por contrato. Otros, como las hortalizas, flores y frutales se insertan en el sistema de intermediarios mencionado, ya sea los producidos en las regiones especializadas 
(jitomate, tomate verde, cebolla, pepino), o a pequeña escala en diversas regiones (calabacita, nardo, rosa, crisantemos, cempasúchil, chile morrón, duraznos, aguacate, etcétera). Una parte importante de las cosechas se ofrece en las plazas de todo el estado, en las carreteras o en las ciudades cercanas a su producción, especialmente si no se siembran a gran escala.

Si bien las condiciones de producción en las diferentes regiones son en pequeñas parcelas y con niveles bajos de tecnología y capacidad de inversión de capital, es posible ubicar dos modelos generales, ambos basados en la diversidad y complementariedad, pero con lógicas un tanto diferentes: una especialización diversificada, y otra diversidad a pequeña escala.

La especialización diversificada se ha dado dentro del desarrollo de la horticultura comercial en la región de los Altos de Morelos a partir de la apropiación, bajo condiciones de baja inversión, minifundio y temporal, de un cultivo comercial técnicamente recomendado para manejo en condiciones de riego y alta tecnología. El jitomate -y a lo largo de las últimas décadas hortalizas como el tomate de cáscara, pepino, chile morón- se ha incorporado a este sistema a partir de la experiencia adquirida en el manejo de la tecnología agrícola, especialmente agroquímicos e implementos menores, asegurando la participación en el mercado nacional y el logro de ganancias que con otros cultivos no es posible.

Sin embargo, dada la dificultad de manejo de plagas en estos cultivos, así como la incertidumbre de los precios, existe un permanente alto riesgo de no obtener ganancias y perder todo lo invertido, de esta manera, los horticultores de Morelos han aprendido a combinarlos con cultivos y actividades productivas que no signifiquen altos riesgos y que puedan solventar las pérdidas, cultivos comerciales menos vulnerables en el mercado y productos de autoconsumo. Dada la dificultad de inversión, las familias campesinas han acoplado la siembra de jitomate a una serie subsecuente de cultivos, ganancias y gastos, de manera que unos sostengan a otros, por ejemplo: los ingresos del pepino que tarda dos meses en cosecharse se utilizan para el pago de los agroquímicos del jitomate que tarda cuatro meses; las ganancias del jitomate se invierten en la cosecha del maíz, la venta del maíz se utiliza para solventar las secas y la engorda de algunos becerros, con la venta de estos se pagarán los almácigos de las hortalizas del próximo ciclo, y así sucesivamente.

En cada unidad familiar se establecen características específicas a esta secuencia, pero en todas se aplica la lógica de complementariedad y seriación subsecuente de ganancias y financiamiento. Entonces la especialización diversificada conjunta y complementa procesos productivos, objetivos, recursos y técnicas, permitiendo el sostenimiento, ganancias y reproducción de la familia. 
La modalidad referida como diversidad a pequeña escala no implica una especialización en cuanto al manejo tecnológico y la vinculación al mercado tan clara como en el caso mencionado anteriormente. Se lleva a cabo en diversas regiones en parcelas pequeñas de riego y en los ciclos de temporal, los cultivos pueden ir cambiando de unos años a otros, así como los destinos de éstos; las cuentas de los cultivos no indican ganancias significativas, pero permiten una cierta movilización de dinero para gastos de la casa o próximos cultivos. Cultivarlos representa aprovechar los recursos existentes y complementar los cultivos de autoconsumo, así como las, a veces escasas, ganancias de la venta de maíz.

La producción especializada y diversificada conlleva múltiples procesos de cambios de las pautas tradicionales de cultivo, ya que las prácticas que se llevan a cabo se modifican constantemente de acuerdo con las exigencias del mercado y la generación tecnológica de insumos. Esto implica también uso intensivo y deterioro de recursos por contaminación de agroquímicos e insumos, pérdida de fertilidad del suelo, sustitución de diversidad de milpa y pago de fuerza de trabajo. Como se dijo, estos cultivos significan el vínculo con un espacio de incertidumbre, como el mercado, en el que no tienen nichos de control ni ventaja, pero representa la posibilidad de complementar riesgos y ganancias.

La especialización y diversidad agrícola comercial son resultados regionales del proceso de modernización en la agricultura, representan una adecuación propia y posible a las restricciones estructurales y lógicas de las familias campesinas.

\subsubsection{Empleo agricola y extra agrícola}

La venta de fuerza de trabajo campesina ha existido a lo largo de toda su historia como una manera de complementar ingresos; en etapas históricas anteriores correspondía a la participación mayoritaria como jornaleros agrícolas. Actualmente, la gama de empleos a los que se insertan son tanto urbanos como rurales.

Algunos campesinos complementan su propio ingreso trabajando en las parcelas de su comunidad, especialmente quienes no cuentan con tierra, o los que sólo siembran en temporal y durante el riego no cuentan con labor propia. Algunos jóvenes que van iniciando su vida productiva y no cuentan con recursos o cultivos propios trabajan en parcelas ajenas, sin embargo, el jornaleo agrícola en Morelos lo ejercen en su mayoría trabajadores migrantes de regiones de extrema pobreza como la montańa de Guerrero, la mixteca oaxaqueńa, o Puebla, quienes llegan atraídos por el trabajo requerido en los cultivos hortícolas comerciales. 
Entonces, el empleo de los campesinos morelenses se vincula más al acceso cercano a carreteras y centros urbanos, por lo que la movilidad laboral toma una modalidad pendular con retornos diarios o semanales de algunos integrantes de la unidad familiar, por temporadas, hacia el empleo no agrícola, como albañilería, empleados en empresas y negocios de distinta magnitud, o de servicios, en gasolineras, puestos de venta, transportes, etcétera.

Como en otras regiones del país, en Morelos quienes más salen son los jóvenes, después de estudiar (primaria o secundaria) deciden no continuar la vocación agrícola y buscan empleo fuera, empezando dicha búsqueda con recomendaciones familiares. De acuerdo con el crecimiento de las familias y la restricción de la tierra, algunos optan por buscar empleos externos, en urbes cercanas o cabeceras municipales, mientras más lejos implica mayor gasto del pasaje o estancia, pero es mejor que el desempleo.

Las opciones de trabajo no agrícola para las mujeres de las comunidades de estudio no son precisamente diferentes que las que tienen los hombres, se llevan a cabo bajo condiciones especiales de permisibilidad al interior de las unidades familiares. Las aspiraciones de las jóvenes se encuentran en tener un empleo cercano, aunque, las posibilidades no son muchas y el trabajo lejos de sus pueblos no siempre les es permitido. Sin embargo, se dan casos de algunas muchachas que rompen estas trabas y logran trabajar en las ciudades, en la labor doméstica, maquilas o fábricas, si bien no son la mayoría, sí se empieza a abrir como opción.

En algunas ocasiones, las salidas son semanales, quincenales, mensuales o mayores; estas opciones implican pagos de habitaciones, ausencias temporales con regresos continuos. En otros casos, pueden derivar en ausencias mayores o definitivas de la comunidad; la familia cambia de residencia o se producen rupturas, nuevos arreglos; las distancias y temporalidades se definen en función de las posibilidades internas, los riesgos y soluciones que en el camino migratorio se establecen. Entonces, las necesidades laborales obligan a que una parte de la población busque opciones fuera de los pueblos pero la persistencia de comunidades y de núcleos familiares les da posibilidades para regresar.

La salida de los hijos a Estados Unidos parece ser una tendencia a considerar en la actualidad y en el futuro inmediato, significa una oportunidad para tener acceso a una casa propia, el ahorro para iniciar una nueva familia; aunque también representa preocupación y hasta cierto punto frustración al no poder contar con un patrimonio (la tierra) y oportunidades en su propio pueblo.

En todas las comunidades se reconoce la opción de migración, pero no se asume como la aventura obligada. Algunas familias tienen varios 
hijos o parientes en Estados Unidos, otras no y prefieren no considerarlo. Se puede decir que, si bien en algunos lugares de Morelos la migración es mucho más notoria, las redes sociales que aseguran y potencian esta opción, se encuentran en formación.

Las salidas de la población, en general, implican cambios, nuevas perspectivas entre los jóvenes, modificación de costumbres y rutinas diferentes ya no regidas únicamente por el temporal; permiten el sostenimiento de un espacio restringido, aunque no genere directamente procesos de desarrollo local, pues implica solamente inyección de ingresos o salida de fuerza de trabajo que no puede retenerse.

En el marco regional urbano, industrial, comercial y de comunicación se abren ofertas de empleo aunque signifiquen inserciones desventajosas para los campesinos bajo condiciones laborales sin garantías laborales y salarios justos. Estas opciones complementan el sostenimiento de las actividades agrícolas y de autoconsumo, así como la reproducción campesina misma; son una respuesta construida ante las restricciones de acceso a la tierra de todos los campesinos de las comunidades y ante el contexto de ausencia de inversión, créditos productivos y políticas de desarrollo hacia el campo.

\section{Conclusiones}

Como se ha podido ver, la cultura campesina cambia pues ya no sólo se vive de manera tradicional en el pueblo. Hoy se observan equilibrios nuevos entre los cambios urbanos y las innovaciones tecnológicas, y el ritmo peculiar dado por el arraigo a la tierra, las pautas de la naturaleza y la memoria. La población campesina, vinculada a las dinámicas globales, vive un ritmo contradictorio al de la sociedad general, pues sigue dependiendo y se relaciona estrechamente con las fuerzas imprevisibles de la naturaleza. Por otro lado, el eje de los cambios actuales busca pasar por encima de las leyes naturales a través del desarrollo científico y tecnológico, obligándola a cambiar y al mismo tiempo a guardar elementos propios al tratar de enfrentar las nuevas incertidumbres.

Para los campesinos de Morelos, subsistir ahora requiere abrirse a las dinámicas urbanas, a la modernización tecnológica y al mercado, a partir de la organización de su grupo familiar y de sus propios recursos económicos, redes familiares y cultura, adecuándolas y cambiando.

Las maneras concretas de reproducción campesina entre las diversas unidades familiares son diversas, por lo que dentro del escenario general, los pueblos rurales asemejan un archipiélago de formas vinculadas y diferentes, inmersas en un mar de cambios. Estos comparten lógicas y mecanismos de vinculación al mercado, diversidad de producción, arrai- 
gos, permanencia, pérdidas y dependencia, que en su conjunto definen la especificidad cultural de los campesinos de hoy.

Los dos objetivos de la reproducción campesina revisados (seguridad y obtención de ingresos) se retroalimentan y autosustentan. La seguridad guarda permanencias y posibilita cambios; la obtención de ingresos genera cambios y permite que se sustenten las permanencias. Esta combinación abate riesgos tanto sociales como ambientales que son característicos de grupos campesinos marginados.

El conjunto de la organización de unidad familiar contiene procesos en su interior con sentido propio, que en términos de James Scott (2000) es la voz de los dominados y la resistencia cotidiana que permite subsistir con elementos propios, aún siendo subordinados en escalas macro sociales. Esta voz estaría dada por el conocimiento y uso de los recursos naturales y productivos, por la optimización de esfuerzos y tiempos fuera de parámetros de redituabilidad económica, y por los intercambios y el autoabasto conformantes de maneras económicas no monetarizadas.

El maíz, además de la aportación de una parte de la alimentación y subsistencia, representa un conjunto de relaciones de los campesinos y su familia con los distintos elementos de su cultura. A pesar de la crisis y disminución del cultivo, con éste se organizan los ritmos cotidianos y anuales, las decisiones de las familias, los esfuerzos, y la vida de los pueblos, que de manera concreta se da como una disponibilidad de vida hacia el maíz.

Aún hoy, el maíz es el producto más fuerte y definitivo en los pueblos de Morelos, a pesar de su clara declinación. Este último elemento puede marcar un límite al futuro, y el riesgo de pérdida paulatina hasta que se den nuevos equilibrios.

Las adecuaciones técnicas de los cultivos, los aprendizajes necesarios frente a la comercialización, la adaptación de la cotidianidad ante el empleo externo, las salidas constantes hacia las ciudades, los vínculos con los medios de comunicación, las migraciones, etcétera, son factores de cambio en las familias y comunidades campesinas.

La persistencia de la agricultura comercial representa el riesgo necesario de los agricultores al enfrentarse a un mercado en el que se encuentran en condiciones de desventaja, pero que les permite, algunas veces, obtener ganancias económicas e incluso lograr cierta acumulación.

Sin embargo, no siempre se sortean las dificultades de obtención de ganancias económicas en las actividades agrícolas, lo que implica la necesidad de inserción en los mercados de productos y de fuerza de trabajo en el sector terciario e informal, dando continuidad a una condición histórica de subordinación y desventaja de los grupos campesinos. 
Las salidas laborales y migración representan, de manera predominante, espacios de transformación en tanto introducen nuevas perspectivas en la gente, especialmente en los jóvenes; de igual manera modifican la organización de la unidad familiar al alterar los ritmos diarios y anuales en función del temporal y las actividades agrícolas. También disminuyen la disponibilidad de brazos familiares para ejecutar los trabajos locales, pero dan lugar a ganancias que se invierten en bienes familiares, en las actividades de autoconsumo y en los gastos que las salidas implican. De igual forma, permiten la reactivación de mercados locales y regionales por la inversión que en la región se hace de los ingresos externos o las remesas obtenidas en Estados Unidos.

Los vínculos con los mercados y las urbes implican cambios importantes para los pueblos, pues la predominancia del mercado presiona las formas productivas y de vida rurales al ser vistas como obsoletas e improductivas; sin embargo, los campesinos, con maneras peculiares de producir, vincularse al mercado y vivir su propia tradición, intentan permanentemente equilibrios dinámicos y complejos entre ganancias, riesgos y seguridad.

Con ello se definen situaciones y maneras diversas de complementar la reproducción entre los cambios y las permanencias, conformando el panorama actual como un campo de contradicciones y construcción de alternativas de desarrollo, en tanto representan opciones culturales con objetivos y procesos de decisión tomados a partir de elementos tanto estructurales como coyunturales, preferencias tradicionales y necesidades de cambio.

De igual modo, consideramos que dichas estrategias marcan, hasta hoy, la viabilidad de una forma de vida campesina que ha subsistido como producto del capitalismo, con grandes cambios para permitir brindar múltiples servicios a la sociedad en general y a la propia reproducción de sus pobladores.

\section{Bibliografía}

Bartra Verges, Armando (2010), Campesindios. Aproximaciones a los campesinos de un continente colonizado, Instituto para el Desarrollo Rural de Sudamérica, La Paz.

Conapo (Consejo Nacional de Población) (2000), "Morelos: indicadores sobre migración a Estados Unidos, índice y grado de intensidad migratoria por municipio", Índices de intensidad migratoria México-Estados Unidos 2000, México, http://www.conapo.gob.mx/ 
es/CONAPO/Indices_de_Intensidad_Migratoria_Mexico-Estados_Unidos_2000, 10 de enero 2010.

Contreras-MacBeath, Topiltzin, Fernando Jaramillo Monroy y José Concepción Boyás-Delgado (coords.) (2006), La diversidad biológica en Morelos. Estudio del estado, Comisión Nacional para el Conocimiento y Uso de la Biodiversidad-Universidad Autónoma del Estado de Morelos-Comisión Estatal de Agua y Medio Ambiente, Cuernavaca.

Fox, Jonathan y Libby Haight (coords.) (2010), Subsidios para la desigualdad: Las politicas públicas del maiz en México a partir del libre comercio, Woodrow Wilson International Center for Scholars, México.

Guzmán-Gómez, Elsa (2004), "Mujeres, trabajo y organización familiar: los traspatios en Ahuehuetzingo, Morelos", en Blanca Suárez y Paloma Bonfil (coords.), Entre el corazón y la necesidad. Microempresas familiares en el medio rural, GIMTRAP-Fundación Ford, México, pp. 1-49.

Guzmán Gómez, Elsa y Arturo León-López (2008a), Campesinos jitomateros. Especialización diversificada en los Altos de Morelos, Plaza y Valdés-Universidad Autónoma del Estado de Morelos, México.

Guzmán-Gómez, Elsa y Arturo León-López (2008b), "Prácticas comunitarias del maíz en Morelos", en Gisela Espinosa et al., Experiencias campesinas frente al neoliberalismo, UAM unidad Xochimilco, México, pp. 263-283.

Hervieu, Bertrand y Jean Viard (2001), L'archipel paysan. La fin de la république agricole, Éditions de l'Aube, Paris.

INEGI (Instituto Nacional de Geografía y Estadística) (1994), "Censo Ejidal 1991”, INEGI, Aguascalientes, http://www.inegi.org.mx/ est/contenidos/proyectos/Agro/ca1991/Resultados_Ejidal/default.aspx, enero 2010.

INEGI (Instituto Nacional de Geografía y Estadística) (2003), "Censo General de Población y Vivienda 2000”, INEGI, Aguascalientes, http://www3.inegi.org.mx/sistemas/tabuladosbasicos/tabentidad. aspx?c=33144\&s=est, 12 enero 2010. 
INEGI (Instituto Nacional de Geografía y Estadística) (2008), “Censo Ejidal 2007”, INEGI, Aguascalientes, http://www.inegi.org.mx/ est/contenidos/proyectos/Agro/ca2007/Resultados_Ejidal/default.aspx, 12 enero 2010.

INEGI (Instituto Nacional de Geografía y Estadística) (2011), "Censo de Población y Vivienda”, INEgI, Aguascalientes, http://www3.inegi. org.mx/sistemas/tabuladosbasicos/default.aspx?c= 27302\&s=est, octubre 2011.

León-López, Arturo y Elsa Guzmán-Gómez (1999), “El papel de la alimentación en la reproducción y desarrollo campesino", en Luz María Espinosa Cortés (coord.) Sector agropecuario y alternativas comunitarias de seguridad alimentaria y nutrición en México, Plaza y Valdés-InNSz-UAm unidad Xochimilco, México, pp. 267-283.

León-López, Arturo y Elsa Guzmán-Gómez (2004), "Huertas en el desarrollo urbano de la región de la barranca del Amatzinac", en Gabriela Arias Hernández et al. (coords.), Agricultura urbana y periurbana en México: Segundo encuentro nacional; la agricultura urbana como estrategia organizativa para el abasto de alimentos, la supervivencia familiar-local, sostenibilidad ambiental y las politicas públicas, Universidad Autónoma Chapingo, Texcoco, pp. 107-117.

León-López, Arturo y Elsa Guzmán-Gómez (2005), “Multiactividad y migración en el poniente de Morelos", Revista Politica y Cultura, (23), UAm unidad Xochimilco, México, pp. 103-120.

Morales-Tapia, Silvino (2007), "Los huertos de traspatio campesinos. Manejo, trabajo y organización familiar en Quilamula, una comunidad de la Reserva de la Biósfera Sierra de Huautla, Morelos”, tesis de maestría, Universidad Autónoma del Estado de Morelos, Cuernavaca.

Presidencia de la República (2008), $2^{\circ}$ Informe de Gobierno. Información del Sistema de Cuentas Nacionales, Gobierno Federal, México.

Rubio, Blanca (2006), "Una teoría con campesinos: los despojados del nuevo imperialismo", en Alasru. Nueva época. Análisis latinoamericano del medio rural. El debate teórico rural contemporáneo, (3), Universidad Autónoma de Chapingo-Alasru, Texcoco, pp. 81-120. 
Sánchez-Saldaña, Kim y Adriana Saldaña-Ramírez (2010), Buscando la vida: productores y jornaleros migrantes en Morelos, Plaza y ValdésUniversidad Autónoma del Estado de Morelos, México.

Scott, James (2000), Los dominados y el arte de la resistencia, Era, México.

SIAP-Sagarpa (Servicio de Información Agroalimentaria y Pesquera-Secretaría de Agricultura, Ganadería, Desarrollo Rural, Pesca y Alimentación) (2010), "Producción agrícola", <http://infosiap. siap.gob.mx/ventana.php?idLiga $=1042 \&$ tipo $=1>, 25$ de octubre de 2011.

Recibido: 5 de abril de 2010. Reenviado: 27 de octubre de 2011. Reenviado: 3 de noviembre de 2011. Aceptado: 23 de febrero de 2012.

Elsa Guzmán-Gómez. Doctora en antropología por el Instituto de Investigaciones Antropológicas de la Universidad Nacional Autónoma de México. Actualmente es profesora investigadora de la Facultad de Ciencias Agropecuarias de la Universidad Autónoma del Estado de Morelos. Es integrante del Sistema Nacional de Investigadores, nivel i. Sus líneas de investigación son: estrategias campesinas de vida en el estado de Morelos y resguardo campesino del maíz en Morelos. Entre sus publicaciones recientes se encuentran, en coautoría: "Determinantes para la no renegociación del TLCAN", Revista Argumentos, núm. 57, uAM unidad Xochimilco, México, pp. 175-208 (2008); en coautoría, "Desarrollo campesino y construcción de ciudadanía en el norte de Morelos", Revista Argumentos, núm. 61, uam unidad Xochimilco, México, pp. 223-246 (2009); en coautoría, "Prácticas comunitarias del maíz en Morelos" en Gisela Espinosa et al., El desarrollo rural desde la mirada local, UAM unidad Xochimilco, México, pp. 263-284 (2009); "Los productores campesinos de Morelos. Sobre estrategias y mercado” en Kim Sánchez y Adriana Saldaña, Buscando la vida en los campos de Morelos, Uaem-Plaza y Valdés, México, pp. 19-59 (2009); de su autoría Resistencia, permanencia y cambio. Estrategias campesinas de vida en el poniente de Morelos, UAEM-Plaza y Valdés, México, (2005); en coautoría, Campesinos jitomateros. Diversidad especializada en los Altos de Morelos, uAem-Plaza y Valdés, México (2008); en coautoría Gestión social y procesos productivos, UAEM, México (2011); en coautoría, Imágenes del Morelos rural. Una construcción social del paisaje, Juan Pablos editor-Uaem, México, (2012). 
Arturo León-López. Doctor en desarrollo económico y social por la Universidad París I Pantheon-Sorbonne. Fungió como profesor investigador en el posgrado en Desarrollo Rural de la Universidad Autónoma Metropolitana unidad Xochimilco. Integrante del Sistema Nacional de Investigadores, nivel II. Entre sus líneas de investigación se encuentran: estrategias productivas campesinas, organización de productores y agricultura y mercados mundiales. Algunas publicaciones recientes: "Determinantes para la no renegociación del TLCAN", Revista Argumentos, núm. 57, uAm unidad Xochimilco, México, pp. 175-208 (2008); en coautoría, "Desarrollo campesino y construcción de ciudadanía en el norte de Morelos", Revista Argumentos, núm. 61, uAm unidad Xochimilco, México, pp. 223-246 (2009); en coautoría, "Prácticas comunitarias del maíz en Morelos" en Gisela Espinosa et al., El desarrollo rural desde la mirada local, UAm unidad Xochimilco, México, pp. 263-284 (2009); Los retos del desarrollo rural, UAM unidad Xochimilco, México (2005); en coautoría, Diversidad rural. Estrategias económicas y procesos culturales, UAM unidad Xochimilco, México (2006); en coautoría, El desarrollo rural desde la mirada local, UAM unidad Xochimilco, México (2009); en coautoría, Campesinos jitomateros. Diversidad especializada en los Altos de Morelos, uAem-Plaza y Valdés, México (2008); Espacios públicos y estrategias campesinas ante la crisis en México, uAm unidad Xochimilco, México (2010); en coautoría, Imágenes del Morelos rural. Una construcción social del paisaje, Juan Pablos editor-UaEm, México (2012). 